\title{
OTher Minds ANd PERCEIVEd IDENTITy
}

\author{
Anil Gomes \\ Birkbeck College, London
}

Forthcoming, Dialectica [accepted 2009]

\begin{abstract}
Quassim Cassam has recently defended a perceptual model of knowledge of other minds: one on which we can see and thereby know that another thinks and feels. In the course of defending this model, he addresses issues about our ability to think about other minds. I argue that his solution to this 'conceptual problem' does not work. A solution to the conceptual problem is necessary if we wish to explain knowledge of other minds.
\end{abstract}

\section{Introduction}

Philosophers have often distinguished two problems of other minds, one epistemological and one conceptual. The epistemological problem asks: how is it possible to have knowledge of other minds? The conceptual problem asks: how is it possible to think about other minds? The relation between these questions is unclear, but perhaps it is fair to say that there is a prima facie reason for taking the conceptual problem to be more basic. For knowledge claims presuppose conceptual capabilities, so any obstacle which prevents thought about other minds will, a fortiori, prevent knowledge of them.

In his recent discussion of these issues, Quassim Cassam reverses this order of engagement. ${ }^{1}$ His concern is explaining the possibility of knowledge of other minds, and in the course of addressing that 'how-possible' question,

1 (Cassam, 2007: ch.5). All references to this work. 
issues arise regarding our possession of mental concepts. But the primary focus is knowledge, and any answer to the conceptual problem takes place in this framework. In this paper I will set out Cassam's solution to both problems of other minds, and provide some reason for thinking his response to the conceptual problem unconvincing. Further attention must be paid to the conceptual problem if we wish to secure knowledge of other minds.

\section{Knowledge of Other Minds}

Cassam addresses the problem of other minds in the course of advocating a certain structure for responding to 'how-possible' questions in epistemology: questions which ask how knowledge of some kind is possible, given supposed obstacles to its existence or acquisition. He endorses a 'multi-levels' response to such questions: first we identify the means by which we come to possess the knowledge in question, then we show that there aren't any obstacles to the possibility of gaining knowledge by such means and finally we identify the background enabling conditions necessary for this method to serve as a means of coming to know. A successful response to a 'how-possible' question will involve philosophical work at each of these three levels. ${ }^{2}$

In the case of other minds, Cassam's concern is with $\left(\mathrm{HP}_{\mathrm{om}}\right)$ : how is knowledge of other minds possible? Cassam's solution is a perceptual model of knowledge of other minds, one on which 'it's possible to know that others think and feel by perceiving that others think and feel' (p.158). Knowledge of other minds is possible because we can sometimes see what another thinks and feels, and thereby know that another thinks and feels. Identifying visual perception as a source of knowledge of other minds is a first level response to the question: it identifies a means by which we can know that others think and feel. ${ }^{3}$

However, simply identifying perception as a source of knowledge of other minds is not sufficient for addressing $\left(\mathrm{HP}_{\mathrm{om}}\right)$, since there are supposed obstacles to the possibility of seeing and thereby knowing that someone is angry, say. Cassam canvases two such obstacles: that one cannot see that $\mathrm{A}$ is angry unless one sees his anger, something which cannot be done. And that seeing that $\mathrm{A}$ is angry requires eliminating the possibility that he is a zombie,

\footnotetext{
2 See (Cassam 2007: ch.1)

${ }^{3}$ Cassam introduces the perceptual model as one on which a subject can perceive that another thinks and feels, clarifying this as the claim that 'one can sometimes know what others are thinking or feeling by visual means' (2007: p.170, my emphasis).
} 
something which also cannot be done. If either of these obstacles is genuine, then one cannot see, and thereby know, that another is angry.

Cassam's response is to dissipate these obstacles, that is, to deny each of the claims. In the case of the first obstacle, that involves arguing that one can see that $A$ is angry without seeing his anger. And in the case of the second, it involves arguing that seeing that $\mathrm{A}$ is angry does not require eliminating the zombie possibility. In dissipating both of these obstacles, Cassam draws heavily on Dretske's notion of primary epistemic seeing. In epistemic seeing, one sees that something is the case. Primary epistemic seeing is the case where we see 'that $\mathrm{b}$ is $\mathrm{P}$ by seeing $b$ itself; the contrast is with those cases of secondary epistemic seeing where 'we see that $\mathrm{b}$ is $\mathrm{P}$ without seeing $b$ ' (Dreske 1969: pp.79-80). ${ }^{4}$ It is the nature of primary epistemic seeing which enables Cassam to deny the purported obstacles.

According to Dretske's account, primary epistemic seeing is to be understood as follows:

$S$ sees that $b$ is $P$ in a primary epistemic way only if: i. b is $P$, ii. $S$ sees $_{n}$ b, iii. The conditions under which $S$ sees $_{\mathrm{n}} \mathrm{b}$ are such that $\mathrm{b}$ would not look, $\mathrm{L}$, the way it now looks to $S$ unless it was $\mathrm{P}$, iv. S, believing the conditions are as described in (iii), takes b to be P. (Dretske 1969: taken from pp.79$88)^{5}$

Applying this to the case of the mental attributes of persons, we have the claim that $S$ sees that $A$ is angry only if $i$. A is angry, ii. $S$ sees $A$, iii. the conditions under which $S$ sees $A$ are such that $A$ would not look, $L$, the way he now looks to $S$, unless A were angry, and iv. S, believing that the conditions are as described in (iii), takes $\mathrm{A}$ to be angry. When these conditions are met it is possible to see, and thereby know, that another is angry. Such is our perceptual knowledge of other minds.

Cassam's dissipation of the obstacles countenanced draws upon this notion of epistemic seeing. In order to see that A is angry, the four conditions outlined above must be met. It isn't a requirement, therefore, that one see A's anger in order to see that he is angry, in the same way that seeing that the metal is hot doesn't require one to see its heat. The first obstacle can be

${ }^{4}$ Cassam's sole concern is primary epistemic seeing, since it is in primary epistemic seeing that one acquires knowledge by perceiving the object in question. See (Dretske 1969: pp.8081).

${ }^{5}$ Sees $_{\mathrm{n}}$ denotes 'non-epistemic' or 'simple' seeing. 
rejected. ${ }^{6}$ Similarly, eliminating the possibility that $\mathrm{A}$ is a zombie would involve knowing that the third condition is fulfilled. So if one can't eliminate that possibility, then one can't know that the third condition pertains. But the account of epistemic perception says only that one must believe that the third condition is fulfilled, not that one knows that it is so. 'If I don't know that the third condition is fulfilled then I don't know that I see that $[\mathrm{A}]$ is angry, but I nevertheless see that he is angry.' (p.168). The zombieelimination requirement is not a genuine requirement on epistemic perception, thus the second obstacle can be rejected. ${ }^{7}$

One might question either of these moves, but for the purposes of this paper, all I want to note is the extent to which Cassam's dissipation of the supposed obstacles to his perceptual model draws heavily on the notion of epistemic perception. This is important because so far we have only addressed the supposed obstacles to a perceptual response to $\left(\mathrm{HP}_{\mathrm{om}}\right)$. In order to complete the response and secure knowledge of other minds, we must identify the necessary background conditions under which it is possible for epistemic perception to serve as a source of knowledge of other minds. These enabling conditions explain what makes it possible for epistemic perception to serve as a source of the knowledge in question, and thus complete our response to $\left(\mathrm{HP}_{\mathrm{om}}\right)$.

What are the enabling conditions for epistemic perception? We can identify one by noting that seeing that someone is angry requires possession of the concept of anger. Moreover, it requires that your possession of the concept of anger is such that you can think of it as being potentially applicable both to yourself and to others. In order to think of anger in this way, one must grasp a sameness or identity condition: you must be able to think of another's state of anger as being of the same type as your own. So one enabling condition on seeing that someone is angry is a grasp of this sameness relation. Cassam terms this the Identity Condition. 'What the identity condition says is that it wouldn't be possible for me to see that $[\mathrm{A}]$ is angry unless I can think of the state that he is in when he is angry as a state of the very same type as I am in when I am angry.' (p.172). Grasp of this sameness condition is necessary for

\footnotetext{
${ }^{6}$ (Cassam 2007: pp.162-5). Cassam suggests that there is a sense in which you see his anger, since you see A venting, or manifesting, his anger. But this is only seeing his anger 'in a sense' (p.164).

${ }^{7}$ (Cassam 2007: pp.165-171). Since seeing that $\mathrm{p}$ is a way of knowing that $\mathrm{p}$, it follows that if you don't know that the third condition is fulfilled, you don't know that you know that A is angry.
} 
possession of the concept of anger, and therefore necessary for someone to perceive that another is angry.

We have identified one enabling condition on the possibility of epistemic perception serving as a source of knowledge of other minds. But an immediate question arises, namely, how is it possible to grasp this sameness condition? As Cassam puts it, 'how is it possible for me to understand that I am ascribing states of the same type in the two cases? How is grasp of this sameness relation possible?' (p.179). Consideration of the enabling conditions of epistemic perception leads us directly to this question: a question which brings in issues about our ability to think of another mind. The conceptual problem of other minds enters at the third level of Cassam's 'multi-levels' approach.

One reason people have been tempted to ask the question 'how is it possible to think about other minds?' is because they have seen a problem with accounting for our grasp of mental concepts, where mental concepts are understood to apply both to others and to ourselves. This is the question that arises for Cassam: how is it possible to grasp such an understanding of the mental? The question has force given a prima facie obstacle to our attaining such an understanding, namely that our ascription of mental concepts to others proceeds on the basis of different grounds to our ascription of mental concepts to ourselves. Given this difference in ascription-conditions, what gives us ground for thinking that our applications of mental concepts are univocal?

One immediate way to dissipate this obstacle is to deny that self and otherascriptions proceed in a different manner; to claim instead that I ascribe anger to myself on the same basis that I ascribe it to others. Ryle endorses such a claim, arguing that the differences between the ways in which we find out about our own minds and the ways we find out about others are 'differences of degree, not of kind' (Ryle 1949: p.179). The knowledge we have of our own mind stems not from any privileged access, but from the more mundane fact that we are often better placed than others to observe the same corpus of evidence. And, as Ryle suggests, once one denies that the way we find out about our own minds is fundamentally different from the way we find out about others, the conceptual problem dissolves, for 'no metaphysical Iron Curtain exists compelling us to be absolute strangers to one another.' (p.181). 
But this dissipation seems too extreme, denying as it does that there is anything distinctive about our first-person application of mental concepts. ${ }^{8}$ Certainly there are occasions on which the way I find out about my own mind is comparable to the way I find out about others, as when I come to realise that I am angry with my friend by noticing my clenched fists and clipped sentences. But this seems to be the exception rather than the norm. In general we take it not only that we know our own minds better than other people's, but that we know about them in a different way, one which explains the default authority we have with regards to our own selfascriptions. And as long as one thinks that there is a distinctive way in which we self-ascribe mental predicates, then the conceptual problem can be raised: how is it that we understand our ascriptions of such concepts to be univocal given the different grounds for assertion?

This problem arises for any account of the self-ascription of mental concepts which falls short of Ryle's claim that there is no difference between the ways in which we find out about our own minds and the ways in which we find out about others. For rejecting Ryle's claim amounts to an insistence that there is something distinctive about the way in which we find out about our own mental life. And that leaves open Cassam's question of how it is possible for us to grasp the Identity Condition given the fundamentally different grounds for assertion in each case. Note that this applies equally to those perceptual models of self-knowledge that want to hold onto something distinctively first-personal about introspection. For although such models introduce introspection by analogy with perception, nevertheless there is often claimed to be an essentially first-personal indexical element to introspective representations, an element which explains the fact that introspection is a distinctive way of gaining self-knowledge. And as long as self and other ascriptions of mental predicates proceed on fundamentally different grounds, then the question retains its force. ${ }^{9}$

This, then, is how the conceptual problem of other minds enters the dialectic. In order to explain how we can see that another is angry, we have to address the question of how it is possible to grasp the concept of anger, given the difference in assertibility-conditions. Cassam's solution is to overcome the obstacle, that is, to show that there is a way we can come to

\footnotetext{
${ }^{8}$ Cassam (p.179) concurs.

${ }^{9}$ See (Gertler 2009) and (Shoemaker 1994) for discussion and criticism of perceptual models of introspection, and (Wright et.al. 1998) for discussions of self-knowledge more generally. Thanks to a reviewer for raising the issue of self-knowledge.
} 
grasp the sameness condition. Suppose, Cassam says, that I can see that A is angry, and I become angry at the way he is being treated. What do I see? 'I see that he is angry but that is not all. I also see that he is just as angry as I am. In other words, I see that the state he is in is no different from the state I am in... In such cases, the identity of mental state is a presented or perceived identity, and this is what makes it possible for me to think of [A]'s state and mine as states of the same type.' (p.181).

Here we have a solution to the conceptual problem of other minds. In certain situations, it is possible to see that $\mathrm{A}$ is in the same type of mental state that I am in. This perceived identity suffices for me to grasp the sameness condition and thereby understand that our states are states of the same type. It is therefore possible to grasp the sameness condition, and thus there is no obstacle to grasping the concept of anger. We have a multi-levels response to $\left(\mathrm{HP}_{\mathrm{om}}\right)$ and the perceptual model solution to the possibility of knowledge of other minds can stand.

\section{Perceived Identity}

I do not believe that Cassam's solution to the conceptual problem works. But let me make one thing explicit: Cassam does not claim that the perceived identity of mental states is necessary for us to grasp mental concepts. It may well be that there are other ways to grasp the sameness relation. All he is concerned to show is that it is possible for us to do so, and demonstrating the possibility of grasping such a sameness relation is sufficient for overcoming the supposed obstacle and validating the possibility of epistemic perception providing us with knowledge of another's mind. ${ }^{10}$

To dispute Cassam's solution, then, one has to show that it is not possible to see that A is in the same mental state that I am in. 'Same mental state' here means 'same type of mental state', a phrase which picks out a relation holding between two persons. What is necessary for me to see that A stands

\footnotetext{
10 Although Cassam stresses that perception need only be $a$ means of coming to grasp the sameness relation, he does not mention any other routes. If one thinks that there are many cases in which subjects grasp the concept of anger without having perceived that another is angry whilst being angry themselves, then Cassam's perceived identity solution will seem a touch peripheral.
} 
in this relation to me? Thinking about the conditions necessary to see that this relation holds can highlight some problems for Cassam's account. ${ }^{11}$

\section{Perceived Identity and Seeing Oneself}

Cassam does not provide any account of what is involved in relational epistemic seeing - seeing that a certain relation holds - but given that he draws explicitly on Dretske's account of epistemic seeing in his discussion of other minds, it is natural to turn to Dretske to elucidate relational epistemic seeing. According to Dretske, relational epistemic seeing should be understood on the model of primary epistemic perception discussed above, with the amendment that $S$ sees that $\mathrm{A}$ bears $R$ to $\mathrm{B}$ only if she sees both $\mathrm{A}$ and B. ${ }^{12}$ Seeing the items related is a condition of seeing that the relation holds.

There is some intuitive support for this claim. Consider a case in which one sees that the bookcase is taller than the door. It is natural to think that it is a requirement on someone being in this state that she sees both the bookcase and the door. In particular, it will be a requirement that one sees both the bookcase and the door if you think that, in virtue of seeing that the bookcase is taller than the door a subject also sees that the door is such that the bookcase is taller than it. ${ }^{13}$ For seeing that $\mathrm{A}$ is some way requires one to see $\mathrm{A}$; so seeing that $\mathrm{B}$ is such that $\mathrm{A}$ bears $R$ to it will require one to see $\mathrm{B}$. If seeing that $\mathrm{A}$ bears $R$ to $\mathrm{B}$ entails seeing that $\mathrm{B}$ is such that $\mathrm{A}$ bears $R$ to it, then it will follow that one can see that $\mathrm{A}$ bears $R$ to $\mathrm{B}$ only if one sees both $\mathrm{A}$ and $\mathrm{B}$.

Applying this to Cassam's case of perceived identity has it that I see that A is in the same type of mental state as me only if I can see both A and myself. The first conjunct is unproblematic: it is a condition on seeing that $\mathrm{A}$ is

\footnotetext{
11 To reiterate the point made in n.3, Cassam is concerned to defend the claim that one 'can sometimes know what others are thinking or feeling by visual means' (2007: p.170, my emphasis.) Challenging Cassam's solution involves showing that we cannot visually perceive that $\mathrm{A}$ is in the same mental state as me.

12 (Dretske 1969: pp.140-1). The third condition is correspondingly amended to hold that both $\mathrm{A}$ and $\mathrm{B}$ would not look the way they do relative to one another unless $\mathrm{A}$ bore $\mathrm{R}$ to $\mathrm{C}$.

13 This is an application of what Richard Price terms the reversibility constraint:

'Necessarily, if A is represented as bearing $R$ to $B$, then B is represented as being such that A bears $R$ to it'. For defence and application, see (Price 2005).
} 
angry that I can see A. But what about the condition that I see myself? Is this claim plausible? For it to be true that I am myself an object of primary epistemic seeing, I have to see myself as a possible subject of mental predicates - 'qua subject' as Cassam puts it - and not simply see 'my body'. ${ }^{14}$ If I cannot see myself as a subject, then I cannot see that I am such that A bears the relation of being in the same type of mental state to me - and, by implication above, cannot see that $\mathrm{A}$ bears the relation of being in the same type of mental state to me.

Do I see myself as a subject? Hume famously denied that the self could ever be an object of experience. ${ }^{15}$ But even those who have taken issue with Hume have not gone so far as to claim that we can see ourselves as subjects. Cassam has argued elsewhere that we are intuitively aware and presented to ourselves, qua subjects, as objects in the world, but this intuitive awareness of ourselves as subjects is not based on visual perception. ${ }^{16}$ To make good the claim that I can be an object of epistemic perception, it is not enough that I am aware of myself as a subject in the world, I have to be able to see myself as a subject. And visual perception simply doesn't present the subject in this way.

Consider again the initial puzzlement that generated the conceptual problem. Our question was about how a subject could understand that her self-ascriptions of anger were applications of the same concept that she applies to others, given the different ground for ascriptions. Essential to this way of stating the problem is the thought that self-ascriptions of anger proceed on a different basis to other-ascriptions. So it is no help to Cassam to note that I can see myself in a mirror, since when I see that I am angry in a mirror, my application of the concept to myself proceeds on the basis of observation. The perceived identity solution was meant to explain how I can understand that non-observational self-ascriptions of the concept are applications of the same concept applied to others, and that requires that vision present me as a subject of experience in this sense. But visual experience plays no role in these self-ascriptions of mental properties. ${ }^{17}$

\footnotetext{
${ }^{14}$ Cf. Cassam: 'seeing that the Bursar is angry by seeing what his body looks like wouldn't qualify as primary epistemic seeing since strictly speaking it wouldn't be a case in which I see that the Bursar is angry by seeing him' (p.174).

15 (Hume 1978: p.252)

16 (Cassam 1999)

${ }^{17} \mathrm{My}$ thanks to a reviewer for raising the issue of seeing oneself in a mirror.
} 
Cassam's perceived identity solution to the conceptual problem requires that one be able to see that $A$ is in the same mental state as me. And if it is right that relational epistemic seeing requires one to see both of the objects related, then there is reason to doubt the adequacy of this proposal - for it requires that I see myself as a subject of experience to whom anger can be selfascribed. But visual experience does not present oneself as a subject in this way. So I cannot see that A stands in the relation of being in the same mental state to me.

\section{Perceived Identity and How Things Look}

Perhaps then Cassam could reject the thought that seeing that $\mathrm{A}$ bears $R$ to $\mathrm{B}$ requires one to see both $\mathrm{A}$ and $\mathrm{B}$. We can think of cases in which one sees that the bookcase is taller than one's niece, without the implication that one also sees her at that moment. Or seeing that the runner is ahead of his opponent, where one sees him alone coming round the final bend. If these are genuine cases of epistemic seeing, then one can see that $\mathrm{A}$ bears $R$ to $\mathrm{B}$ without seeing that $\mathrm{B}$ is such that $\mathrm{A}$ bears $R$ to it. ${ }^{18}$

For Dretske, such cases count as cases of secondary relational epistemic seeing: cases in which one sees that $\mathrm{A}$ bears $R$ to $\mathrm{B}$ without seeing both of the relata. The term 'secondary' is not meant to derogate this type of epistemic perception: in such cases one still sees that something is the case. Rather it is termed secondary because it presupposes or embodies a primary epistemic achievement: one can only see that $\mathrm{A}$ bears $R$ to $\mathrm{B}$ in a secondary sense if one can see (primarily) that something is the case. It is by seeing (primarily) that A has a particular property that one can see that the relation holds. But this secondary epistemic perception is still a kind of epistemic perception, so there is no reason to bar Cassam the use of secondary relational epistemic seeing in explaining his account of perceived identity.

What are the conditions necessary for something to count as an instance of secondary relational epistemic seeing? Dretske summarises the conditions as follows:

18 This section has greatly benefited from the comments of two anonymous reviewers. 
$S$ sees that $b_{1}$ is $R$ to $b_{2}$ in a secondary epistemic way iff $i . b_{1}$ is $R$ to $b_{2}$, ii. $S$ sees $b_{1}$ and sees (primarily) that $b_{1}$ is $Q \ldots$ iii. Conditions are such that $b_{1}$ would not be $Q$ unless $b_{1}$ was $R$ to $b_{2} \ldots$ iv. $S$, believing conditions to be as described in (iii.), takes $b_{1}$ to be $R$ to $b_{2}$. (Dretske 1969: taken from page 154.) ${ }^{19}$

That is, in order for someone to see that $\mathrm{A}$ bears $R$ to $\mathrm{B}$ by only seeing one of the items related, she must see that $A$ has a particular property $(Q)$, such that she can see (primarily) that A is $\mathrm{Q}$, and A would not be $\mathrm{Q}$ unless it bore $R$ to B.

Primary epistemic seeing is thus built into the account of secondary relational epistemic seeing: the subject must be able to see (primarily) that $\mathrm{A}$ is $\mathrm{Q}$ in order to be able to see (secondarily) that $\mathrm{A}$ bears $R$ to $\mathrm{B}$. And according to the conditions set out for something to count as a case of primary epistemic perception, seeing that $\mathrm{A}$ is $\mathrm{Q}$ requires that conditions be such that $A$ would not look the way it now looks to the perceiver unless it was $\mathrm{Q} .{ }^{20}$ It is because $A$ has a look which it would not have were it not $\mathrm{Q}$, that the subject is able to see that $\mathrm{A}$ bears $R$ to $\mathrm{B}$.

Does the case of perceiving that $\mathrm{A}$ is in the same mental state as me meet these conditions? It will be instructive to begin with a simpler case of primary relational epistemic seeing, and work towards the more complicated secondary cases. Consider a case in which one sees two red lights, and sees that they are the same colour as each other. How does this fare as a case of primary epistemic seeing? One sees both relata, and they do bear the relation of being the same colour, so the initial two conditions are satisfied. Of interest, though, is the third condition: that conditions be such that both $\mathrm{A}$ and $\mathrm{B}$ would not look the way they do relative to one another unless $\mathrm{A}$ bore $R$ to $\mathrm{B} .{ }^{21}$ Does the third condition hold for this case? It does, for were $\mathrm{A}$ to lose the relation of bearing $R$ to $\mathrm{B}, \mathrm{A}$ and $\mathrm{B}$ would not look the way they do relative to one another. So one can see that the lights are of the same colour.

When both the related items are seen, then, the relation contributes towards the way the objects look, and one can see that the relation holds. What about cases of secondary relational epistemic seeing, where one sees only one of the

\footnotetext{
${ }^{19}$ I have simplified conditions ii.) and iii.) slightly to focus on those cases where one sees only one of the items related.

${ }^{20}$ See the conditions enumerated in the quote from Dretske in $\$ 2$ above.

${ }^{21}$ This is an amended version of the third condition for non-relational seeing cited in the initial quote from Dretske above.
} 
items related? We can begin by considering those cases in which it seems intuitively appropriate to say that one sees that a relation holds despite only seeing one of the items related. Take the case of seeing that the runner is ahead of his opponent. ${ }^{22}$ Does this count as a case of secondary relational epistemic perception? In order to so count, I must see (primarily) that the runner has a certain property which he would not have were he not ahead of his opponent. Arguably he does possess such a property, namely the property of being alone on this stretch of the track. And he would not look the way he does unless he possessed this property. So I can see that he possesses this property, and thereby count as seeing that he is ahead of his opponent.

In this case, the relation itself doesn't contribute directly to the way things look, since one does not see both of the items related. But it contributes indirectly to the look of the scene, through the presence of property $Q-a$ property which the object would lack were the relation not to hold, and which contributes towards the way the object looks. A similar case can be made for other such intuitively acceptable cases, such as seeing that the bookcase is taller than one's niece and so on. In these cases, the object seen has a particular appearance which it would not have if it did not bear the relation to the unseen object.

How does this bear on the case of seeing that $\mathrm{A}$ is in the same mental state as me? In order for me to be able to see that this relation holds when only seeing A, A must possesses some property $\mathrm{Q}$ which he would not possess were he not in the same mental state as me, and conditions must be such that A would not look the way he looks to me now unless he possessed Q. That is, there must be a way A looks such that he would not possess that look were he not in the same mental state as me. If this claim is true, and if I believe it to be true, then I can see that A is in the same mental state as me.

Is there any plausibility to this claim? There seems no reason to suppose that being in the same mental state as me affects the way that A looks, or, to put it more carefully, that there is a property which contributes towards the way A looks which he would not possess were he not in the same mental state as me. What property could that be? The reason that we are inclined to say that we can see that the runner is ahead of his opponent, or that the bookcase is taller than my niece, is because the items perceived have a certain look which they would lack if the relation did not hold - whether that be the loneliness

${ }^{22}$ The example is Dretske's: (1969: p.142). 
of the runner or the perceptible height of the bookcase. But in the case of perceiving someone who is in the same mental state as me, there isn't a particular look he has which he would lack were we not to be in the same mental state. ${ }^{23}$

Consider the two red lights, but suppose now that one of them is in the other room. Can I see that the lights are the same colour? It seems not, because conditions are not such that the observed light has a look which it would not have were the two not of the same colour. Or amend one of the cases of secondary relational epistemic seeing already discussed. Let's say that my absent niece is prone both to growth spurts and sudden shortenings, such that her height at any particular time is essentially random. Nevertheless she is, at this moment, shorter than the bookcase. Can I see that the bookcase is taller than my niece? Dretske's conditions give us a nice explanation of why I cannot. The bookcase is taller than my niece, and it has some property $\mathrm{Q}$ regarding its height such that I can see (primarily) that the bookcase is Q. Nevertheless, the third condition is not met: conditions are not such that the bookcase would not be $\mathrm{Q}$ unless it was taller than my niece, and thus I cannot see that it is taller than my niece.

The relation of being in the same mental state is like the relation of being the same colour in the case of the lights in different rooms. When one cannot see both of the items related, one cannot see that the relation holds - for there is no property which is both such that the object has a look which it would not have were it to lack the property and is also such that the object would not possess that property were the relation not to hold. To put it more simply, in order for me to see that a relation holds, that relation has to contribute towards the look of the objects seen. The relation of being in the same mental state does not do this. The third condition for epistemic seeing is not met: I cannot see that $\mathrm{A}$ is in the same type of mental state as me.

Regardless, then, of whether seeing that $A$ is in the same mental state as me requires me to see both $A$ and myself, the conditions for relational epistemic seeing are not met by the case where $A$ is in the same mental state as me. Primary relational epistemic seeing requires that $\mathrm{I}$ see both of the items related, but I do not see myself as a subject. Secondary relational epistemic seeing requires that the relation contributes towards the look of the object

\footnotetext{
${ }^{23}$ There's a related problem here which is that, in contrast to other cases of secondary epistemic seeing, the item which is not seen - namely myself, qua subject - has not been previously seen.
} 
seen, but the relation of being in the same mental state does not do this. It is not possible to see that A is in the same mental state as me, so Cassam's claim regarding the perceived identity of mental states should be rejected. That leaves open the question of how it is possible to grasp a concept of anger which applies both to others and ourselves, given the difference in applicability-conditions, a question which must be addressed if we are to explain our knowledge of other minds. The conceptual problem of other minds remains.*

\section{References}

Cassam, Q. 1999, Self and World. Oxford: Oxford University Press

Cassam, Q. 2007, The Possibility of Knowledge. Oxford: Oxford University Press

Dretske, F. 1969, Seeing and Knowing. Chicago: University of Chicago Press Gertler, B. 2009, 'Introspection', in: T. Bayne, A. Cleeremans, and P. Wilken, eds, The Oxford Companion to Consciousness Oxford: Oxford University Press forthcoming

Hume, D. 1978, A Treatise of Human Nature, ed. L. A. Selby-Bigge, revised by P. H. Nidditch Oxford: Oxford University Press

Price, R. 2005, 'Content Ascriptions and the Reversibility Constraint.' Philosophical Perspectives, 19: 353-374.

Ryle, G. 1949, The Concept of Mind London: Hutchinson

Shoemaker, S. 1994, 'Self-Knowledge and Inner Sense' Philosophy and Phenomenological Research, 54: 249-314

Wright, C., Smith, B.C. and Macdonald, C. 1998, Knowing Our Own Minds Oxford: Oxford University Press

\footnotetext{
* My thanks to two anonymous reviewers whose comments have greatly improved the paper.
} 